\title{
Wind Loads on a Medium-Rise Building by Using Five Major International Wind Codes and Standards
}

\author{
A. U. Weerasuriya and M. T. R. Jayasinghe
}

\begin{abstract}
Wind load calculations are done for a medium-rise building with $48 \mathrm{~m}$ height locates in an urban area of Sri Lanka. Five different international wind loading standards were selected to calculate wind loads according to prevailing conditions in Sri Lanka. Available 3 second gust wind speed is converted in to mean hourly wind speed and 10 minutes average wind speed to use selected wind loading standards. The difference of wind load calculations is evaluated by using member forces in columns, beams, and shear walls obtained from a 3-D finite element modelling. The comparison displays that both the Australian standards yields higher wind loads compared to other selected standards. The use of higher terrain-height multiplier for cyclone prone zone 1 contributes much larger member forces compared to other cases. None of the standards exceeds the serviceability criteria, which evaluate by means of drift index.
\end{abstract}

Keywords: Design manual, wind loading standards, Design wind speeds

\section{Introduction}

Medium rise buildings are less sensitive to wind loads compared to high-rise buildings that are subjected to wind loads with same magnitude. Thus, when designing medium-rise buildings, design engineers are conservatively more concerned about vertical loads than lateral loads. As a result, medium-rise buildings employ less sophisticated designs and engineering solutions such as vibration control systems. This makes medium-rise buildings more popular building type in many countries including Sri Lanka. However, extreme wind conditions such as cyclones, tornados impose large wind loads on structures which require designers to design even medium-rise buildings more strongly and safely against wind loads. In such circumstances wind loading standards serve as a main design tool that can be used to design simple building geometries adequately in the absence of sophisticated testing methods such as wind tunnel tests, numerical simulations, etc.

Medium-rise buildings are more common in urban areas of Sri Lanka. Most of these buildings have 2 to 5 storeys but sometimes can be as many storey as 15. Because Sri Lanka is yet to prepare its own wind loading standard, most of these buildings were designed according to various international wind loading standards. These standards range from previous British code of practice CP3 Chapter V- Part2:1972[1] to newest wind loading standards such as EN 1991-1-4:2005[2]. However, this kind of direct adoption of international wind loading standards is questionable because less harmonisation of wind load calculations exist among different wind loading standards. In addition to that, there is no clear agreement of the use of country specific factors which were originally derived for prevailing condition of native country of the standard. Though if one assumed effects of aforementioned factors are less, then the main uncertainty is associated with conversion of available basic wind speeds to different time averaged wind speeds to calculate wind loads as provided in different standards. Because the accuracy of wind load calculation mainly depends on the basic wind, the conversion process should be precise. For an example, the available 3 second gust wind speeds in Sri Lanka needed to be converted in to mean hourly or 10 minutes average wind speeds to use BS 6399-Part 2:1992[3] and BS EN 1991-14:2005[2] respectively.

In this study, wind load calculation is done for a $48 \mathrm{~m}$ height building by using five international wind loading standards. For the calculation purpose existing 3 second gust wind speeds are converted in to 10 minutes and 1 hour wind speeds by using best available methods. The similarities and differences of derived wind loads from five different wind loading standards are evaluated by comparing several types of structural loads including axial force, shear force, bending moment obtained from Finite Element Model (FEM) of the building.

Eng. A.U.Weerasuriya B.Sc.Eng(Hons),M.Sc.(Moratuwa), AMIE(Sri Lanka), PhD candidate, Department of Civil and Environmental Engineering, Hong Kong University of Science and Technology, Hong Kong.

Eng. (Prof). M.T.R. Jayasinghe, B.Sc.Eng(Moratuwa), PhD (Cambridge), C.Eng, MIE(Sri Lanka), Professor, Department of Civil Engineering, University of Moratuwa. 
Following the introduction of this study, section 2 briefly describes the historical and current practices of wind engineering in Sri Lanka. The selected international wind loading standards will be introduced in section 3 . Section 4 illustrates the details of 3-D finite element model. The conversion procedure of 3second gust wind speeds to wind speeds with different averaging time explains in section 5 . Section 6 displays results of member forces obtained from finite element modelling. Finally conclusion illustrates the possible reasons for differences and similarities on wind load calculation done with five different wind loading standards.

\section{Previous practice in Sri Lanka}

Much less attention was paid in designing ordinary buildings against high wind conditions until a massive cyclone hit Eastern and North-Eastern coastal areas of Sri Lanka in 1978. The damage that occurred in 1978 cyclone was huge not only due to underestimation of wind load at design stage but also due to poor workmanship and low quality of building materials [4].The huge losses in both human lives and properties led the production of the first Sri Lankan mandatory document about wind loading" Design of buildings for high winds - Sri Lanka" [5] (Here after referred as design manual).

The design manual was based on the previous British code of practice CP 3 Chapter V - Part 2: 1972[1]. This document consists two main sections; the first section is wind speeds and wind zoning map of Sri Lanka. The second section is about proper design and construction methods to enhance wind resilient ability of a low rise building. These simple techniques are addressing strengthening roof structure, proper fixing of roof covering materials, increase the structural integrity of a low rise building, etc.

One of the important aspects of the design manual is defining basic wind speeds and wind zones in Sri Lanka. However, these basic wind speeds were not derived either by using a properly measured data set or using sound statistical derivation methods. According to the Clarke et al [4] these wind speeds are derived based on information such as damage survey done along the cyclone path, available historical data, considering distance from the coast line and particular location, and using Australian practices. Therefore, some researchers ([6], [7]) raised doubts about magnitude of these wind speeds not only due to the lack of theoretical basis on derivation but also low wind speeds compared to other countries with similar geographical and meteorological conditions. Not only the basic wind speeds but also wind zoning is needed to be revised because some parts of the island may not be free from cyclones anymore as assumed by the design manual. For an example, according to the historical cyclone data, there were two cyclones that entered the country through West coast in 1925 and 1967 [8], which is basically located in wind zone 3 with low probability of hitting by a cyclone.

Addition to the design manual, the most common practice was use of previous British code of practice; CP 3 Chapter V-Part 2: 1972[1]. The quasi-static approach used in CP 3 Chapter V-Part 2: 1972[1], is quite accurate in estimating wind loads on medium-rise buildings but less accurate in predicting behaviour of tall slender structures with dynamic behaviour like modern high-rise buildings [9]. On the other hand, many factors given in previous code of practice such as pressure coefficients, statistical factor, concept of return period has changed with the advance of wind engineering researches done over last few decades. The new standards, which supressed CP 3 Chapter V - Part 2 such as BS 6399-Part 2:1997[3], and EN 1991-1$4: 2005$ [2] incorporate those new data sets and advance methods for wind load calculation which may lead to have better building design. However, even after several decades general practise in Sri Lanka has not changed much yet. Thus evaluating wind loading standards in Sri Lankan conditions is a timely requirement before employing them.

Comparison of different wind loading standards is a common objective completed before adopting any international wind loading standard by a country. A series of technical papers published on Asia-Pacific Conference of Wind Engineering (APCWE) ([10], [11], [12]) focused to harmonize different wind loading standards used in Asia-Pacific region. However, this objective is yet to be accomplished as wind loading standards display significant discrepancies when use them in conditions outside the country of origin. Nevertheless, these Comparisons are done in systematic manner for low-rise, medium-rise, and high-rise buildings separately due to their inherent structural responses ([11], [12]). Tamura el al [10] compared fifteen different wind loading standards in Asia-Pacific region by using $48 \mathrm{~m}$ height building and found that no significant correlation in basic reactions or dynamic response. However, better correlations were observed for peak cladding pressure and force 
coefficient. The comparison done by Kola[13] by using 4 international standards including American, Canadian, Australian and British displayed that design pressures on component and cladding can be differ as large as $200 \%$.

\section{Selected codes and standards for the study}

Many Sri Lankan engineers are using different international wind loading standards to design multi-storey buildings. These standards are ranging from old code of practices such as $\mathrm{CP} 3$ Chapter V - Part 2 to newest code including Euro standard. By considering most popular practices found in Sri Lanka, following codes and standards were selected for the comparison purpose of this study; CP 3 Chapter V - Part 2:1972[1], BS 6399.2:1997[3], AS 1170.2:1989[14], AS/NZS 1170.2:2002[15] and EN 1991-14:2005[2].

CP 3 Chapter V-Part2:1972 [1] is the most familiar practice in Sri Lanka, which uses quasistatic method to calculate wind loads on a building, which is more suitable for evaluating wind loads on low- to medium-rise buildings rather than evaluating structural response of high rise buildings. Many like to continue this practice because of its simplicity and their familiarity about the code. BS 6399.2:1997 [3] is the newer version of the British standard and capable to handle both static and dynamic behaviour of a building. It is necessary to mention that BS 6399.2:1997 [3] was recently suppressed by EN 1991-1-4:2005 [2] not because of technical deficiency of this standard but merely as a strategic decision made to comply with Euro standards. The difference between old Australian standard AS 1170.2:1989 [14] and the latest version AS/NZS 1170.2:2002 [15] is the technique that use to calculate dynamic response of a building. Gust load factor is a more popular method to calculate wind load by considering both fluctuating wind speed and dynamic behaviour of a structure. AS 1170.2:1989 [14] uses this method and it generally uses 3 second gust velocity as basic wind speed. Therefore AS 1170.2:1989[14] can be adopted easily with available wind speed data in Sri Lanka. AS/NZS 1170.2:2002 [15] has changed some factors and methods used in the previous Australian standard and made it a simple document to use. Apart from above reasons, Australian standards cover wide spectrum of wind including cyclones and it is used by many island nations such as Fiji, Solomon Island, etc. However, latest Australian standard uses mean hourly wind speed instead of 3 second gust wind speeds. EN 1991-1-
4:2005 [2] is the first real multinational wind loading standard published in recent past.Not only it compromises many aspects presented in other standards such as BS 6399.2:1997[3], AS/NZS 1170.2:2002 [15]but it also allows adjusting methods and factors according to the prevailing conditions in adopted country by means of a national annex.

\section{Case study}

The majority of medium-rise buildings in Sri Lanka are 2 to 15 storey buildings. Therefore, as a case study, a rectangular shaped office building with $48 \mathrm{~m}$ height and plan dimension of $60 \mathrm{~m} \times 30 \mathrm{~m}$ was analysed by using SAP 2000 software[16] (Figure 1(a)).The same building was used by previous researchers [10]for comparison of wind load calculation by using different international wind loading standards. This building was assumed to be located in anurban area of Sri Lanka. It is also assumed that building has 12 storey with $4 \mathrm{~m}$ floor-tofloor height. All structural components are designed in detail to simulate realistic structural behaviour of the building. Building is designed as a concrete wall-frame structure. Columns and beams act as a frame structure while shear walls are served as walls of the service core. $600 \mathrm{~mm} \times 600 \mathrm{~mm}$ columns are in a $6 \mathrm{~m} \times 6 \mathrm{~m}$ grid from ground floor to 12th floor. All columns are connected by using $600 \mathrm{~mm} x$ $400 \mathrm{~mm}$ (depth $\mathrm{x}$ width) beams at the slab level. Slab thickness is selected as $175 \mathrm{~mm}$ to satisfy deflection criterion. Shear walls are designed as $300 \mathrm{~mm}$ thick reinforced concrete walls around service core of the building. The soft zoning lift system, ducts, and toilets are located within the service core. All columns and beams are modelled in SAP 2000[16] FEM package as frame members with 6 degree of freedom while slab and shear walls are simulated as fournodes shell elements with membrane and platebending behaviour. The diaphragm constraint is used for slabs to preserve membrane action of the slab. Other than the dead load of structural members, super imposed and live loads are applied in model according to the BS6399: Part 1: 1996[3]. Wind loads on building are applied in two orthogonal directions as joint loads at the column - beam junctions on the wind ward and leeward faces separately as shown in Figure 1 (b) .

\section{Basic wind speeds with different averaging time}

Wind loading standards use different time averaged wind speeds to calculate wind loads on structures. However in Sri Lankan context, 
available wind speed data are only 3 second gust wind speeds in three wind zones. Therefore, it is necessary to convert 3 second gust wind speeds to one hour or 10 minutes average wind speeds by using some conversion factors.

Firstly, 3 second gust wind speeds are converted in to mean hourly wind speed as method proposed by Cook [17]. According to Cook's method, the mean hourly wind speed (Vmean) at can be calculated from gust wind speed (VG) as shown Equation (1).

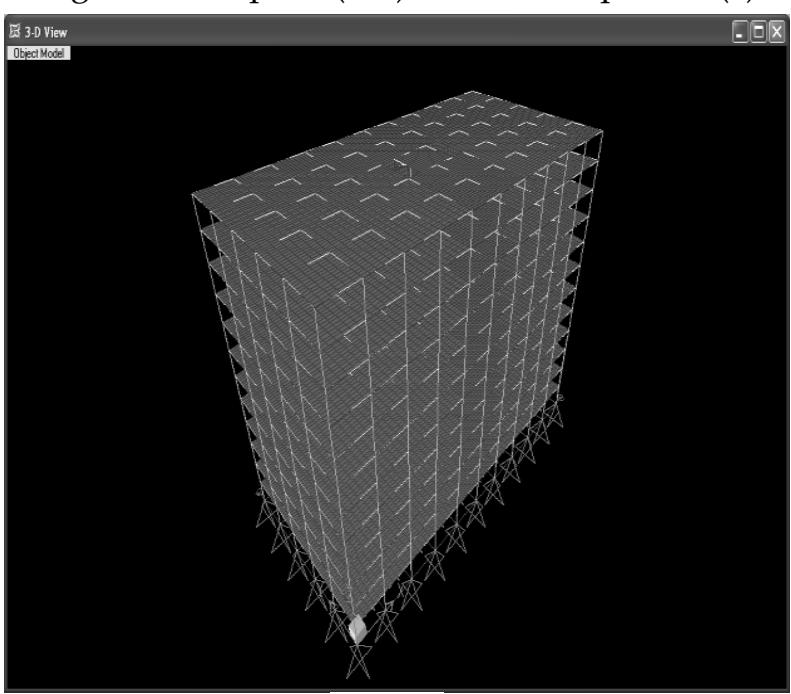

(a)
In this study, it is assumed that building sites in all three zones are within $2 \mathrm{~km}$ from the sea, thus having 1.78 for value of $S_{b}$.

Calculated mean hourly wind speed is converted in to 10 minutes average wind speed by using factor 1.06 as proposed by the Institute of Civil Engineers in United Kingdom (ICEUK) [18]. The wind speeds in all three zones with different average times are shown in Table 1.

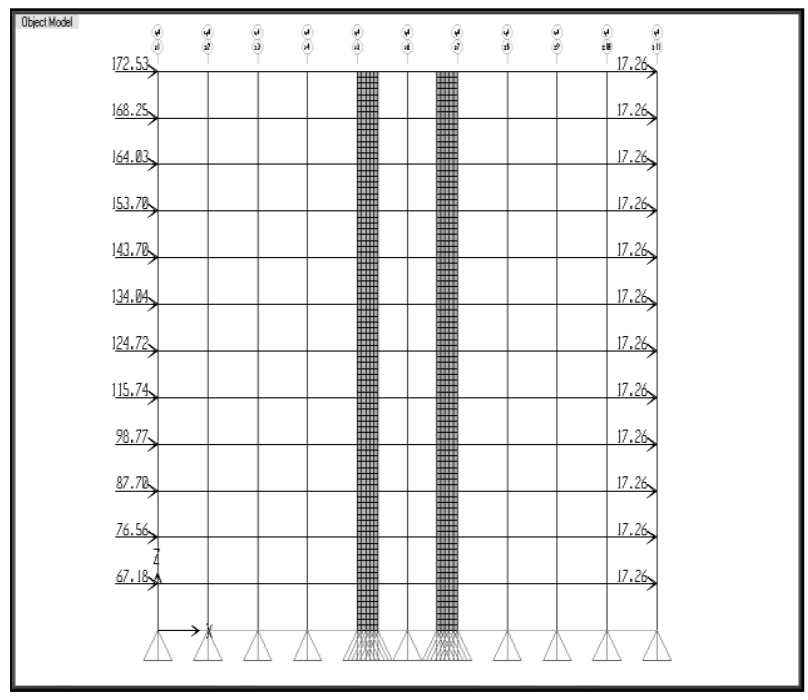

(b)

Figure 1- (a) Finite element 3 - D models of $48 \mathrm{~m}$ height building (b) wind load applied on wind ward and leeward sides of the building (wind load calculation done according to AS/NZS 1170.2:2002 [15] for wind zone 01)

$V_{\text {mean }}=V_{G} / S_{b}$

Where, $\mathrm{S}_{\mathrm{b}}$ is the terrain and building factor at $10 \mathrm{~m}$ height in an open terrain as given in Table 4 of BS 6399.2:1997[3].

The value of $S_{b}$ is only changing with distance from sea toa site of interesting to calculate wind speed.

\section{Results}

\subsection{Wind induced forces}

Wind loading standards only facilitate to calculate wind pressures at different heights of the building. By multiplying these values with

Table 1- Basic wind speeds with different averaging time

\begin{tabular}{|c|c|c|c|c|c|c|}
\hline & \multicolumn{2}{|c|}{ Zone $1\left(\mathrm{~ms}^{-1}\right)$} & \multicolumn{2}{|c|}{ Zone $2\left(\mathrm{~ms}^{-1}\right)$} & \multicolumn{2}{|c|}{ Zone $3\left(\mathrm{~ms}^{-1}\right)$} \\
\hline & 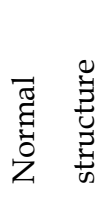 & 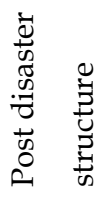 & 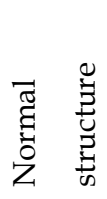 & 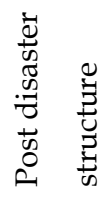 & 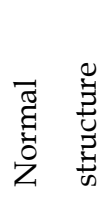 & 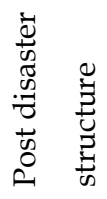 \\
\hline $\begin{array}{l}\text { CP } 3 \text { : Chapter V : Part } 2: 1972 \\
\text { (3 second gust wind speed) }\end{array}$ & 49 & 54 & 43 & 47 & 33 & 38 \\
\hline $\begin{array}{l}\text { BS } 6399-2: 1997 \\
\text { (Mean hourly wind speed) }\end{array}$ & 27 & 30 & 24 & 26 & 18 & 21 \\
\hline $\begin{array}{l}\text { BS EN 1991-1-4:2005 } \\
\text { (10 minutes mean wind speed) }\end{array}$ & 28 & 32 & 25 & 28 & 19 & 22 \\
\hline $\begin{array}{l}\text { AS } 1170.2 \text {-1989 } \\
\text { (3 second gust wind speed) }\end{array}$ & 49 & 54 & 43 & 47 & 33 & 38 \\
\hline $\begin{array}{l}\text { AS/NZS 1170.2:2002 } \\
\text { ( } 3 \text { second gust wind speed) }\end{array}$ & 49 & 54 & 43 & 47 & 33 & 38 \\
\hline
\end{tabular}


corresponding contributory areas will give the wind load at a particular height. However, it is not the actual force experienced by structural members due to their load sharing mechanisms. These actual member forces are important in designing structural members. Structural member forces in columns, beams, and shear walls can be obtained by using 3-D finite element model by applying external loads, in this study it is wind loads.

The member forces used for comparison in this study are maximum values of axial force, shear force and bending moment in columns, shear forces and bending moments in beams, base moment and base shear at the support level and maximum compressive stress in shear walls.

Wind induced forces such in columns, beams, supports and shells on $48 \mathrm{~m}$ high building in all three zones are shown in Figure 2 to 9. All

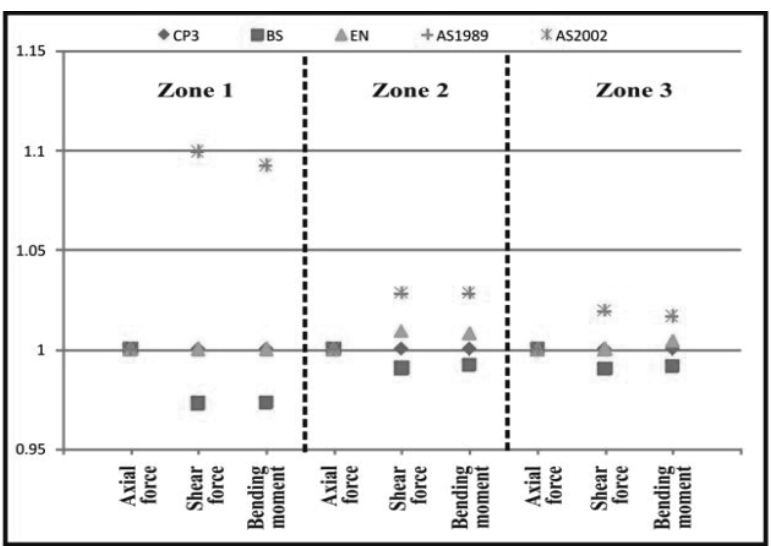

(a) member forces are calculated for the following load combinations:

1. 1.2(Dead loads $[\mathrm{G}])+1.2($ Live load $[\mathrm{Q}])+$ 1.2(Wind load[W])

2. 1.0 (Dead loads[G]) $+1.4($ Wind load $[\mathrm{W}])$

3. 1.4 (Dead loads[G]) + 1.4(Wind load[W]) and 4. Wind load only([W]).

All wind loads are calculated according to provisions given in selected wind loading standards. The higher terrain-height multiplier provided in Australian standards for cyclone prone areas is used only for zone 1 to account the higher probability of hit by a cyclone of that area.

For the purpose of comparison, all results are shown as normalised forces with respect to result obtained for each case for CP 3 Chapter V- Part 2:1972[1].

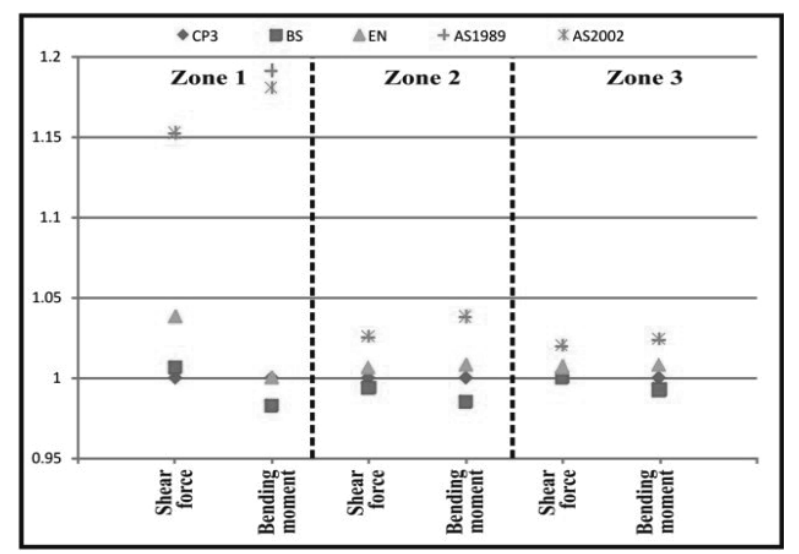

(b)

Figure 2- (a) Column loads (b) Beam loads for load combination 1.2G+1.2Q+1.2W (wind flow perpendicular to $60 \mathrm{~m}$ side)

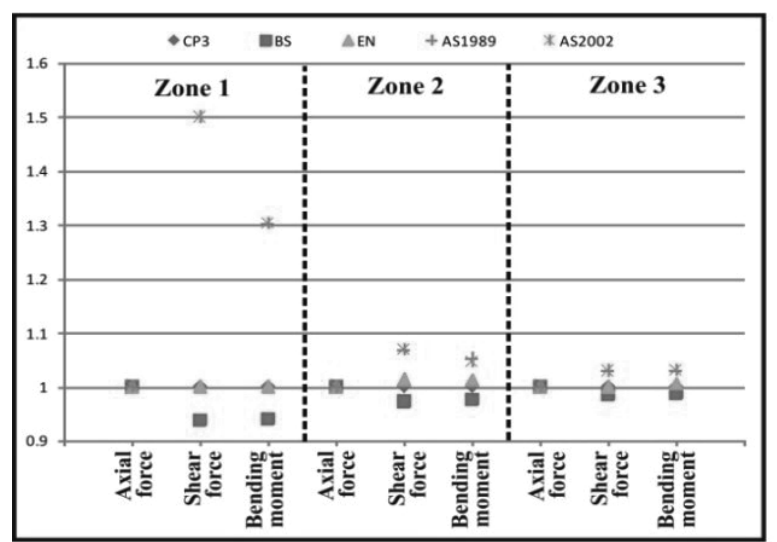

(a)

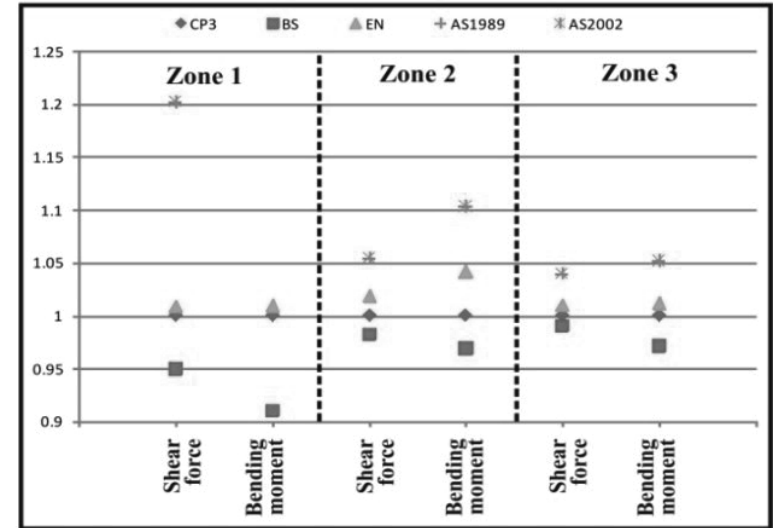

(b)

Figure 3- (a) Column loads (b) Beam loads for load combination 1.0G+1.4W (wind flow perpendicular to $60 \mathrm{~m}$ side) 


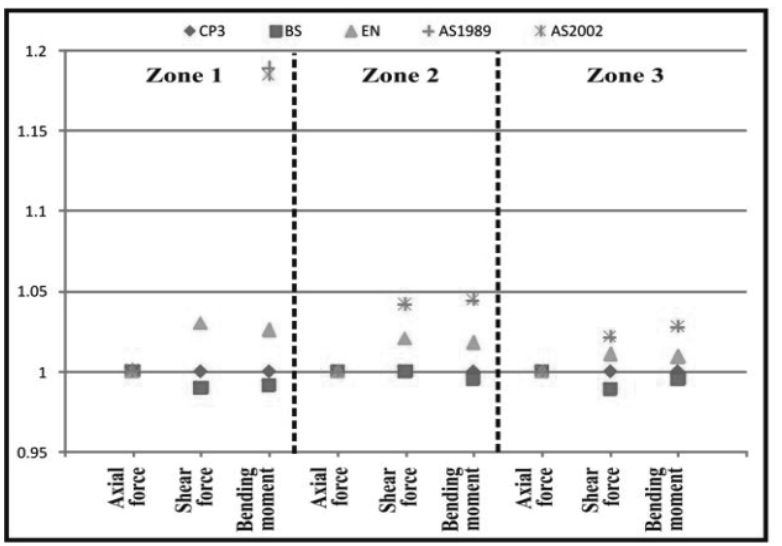

(a)

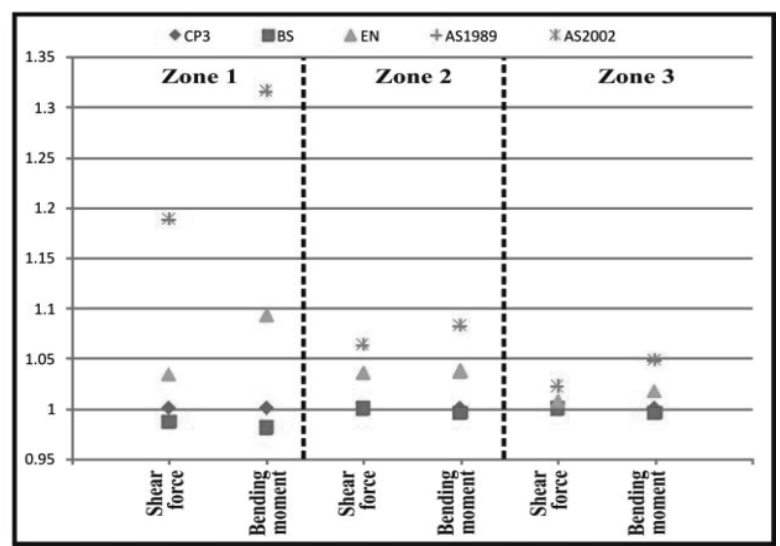

(b)

Figure 4- (a) Column loads (b) Beam loads for load combination 1.4G+1.4W (wind flow perpendicular to $60 \mathrm{~m}$ side)

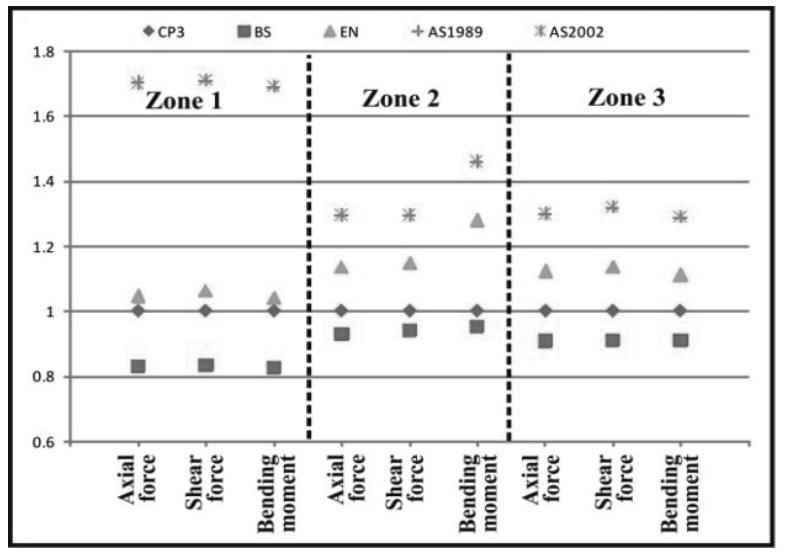

(a)

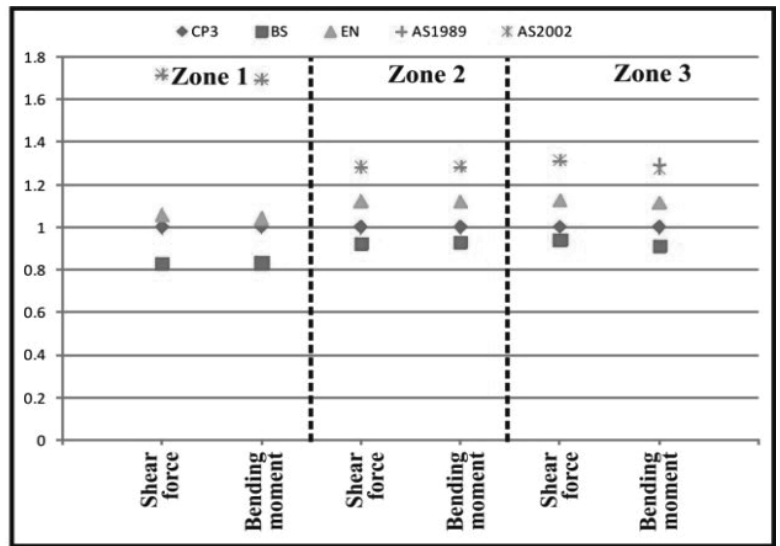

(b)

Figure 5- (a) Column loads (b) Beam loads for wind load only (wind flow perpendicular to $60 \mathrm{~m}$ side)

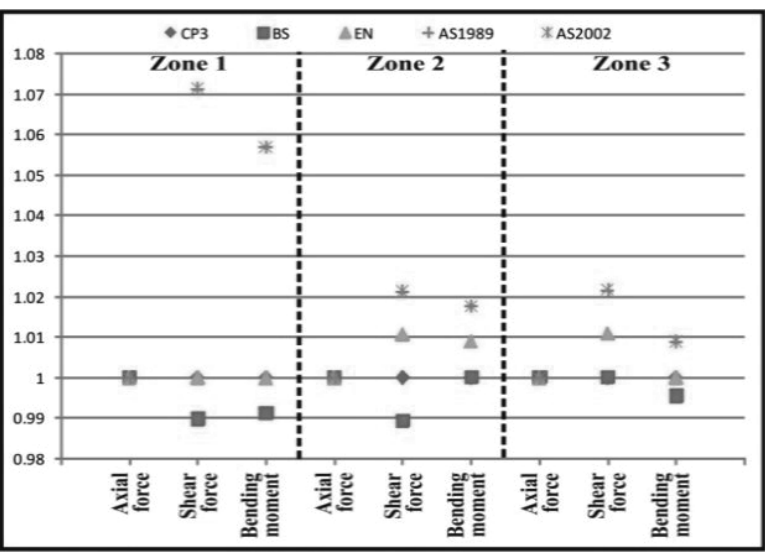

(a)

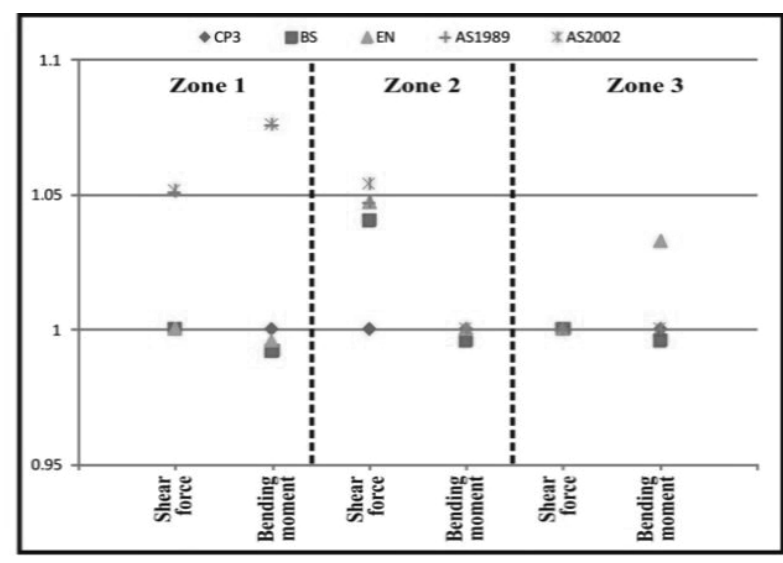

(b)

Figure 6- (a) Column loads (b) Beam loads for load combination 1.2G+1.2Q+1.2W (wind flow perpendicular to $30 \mathrm{~m}$ side) 

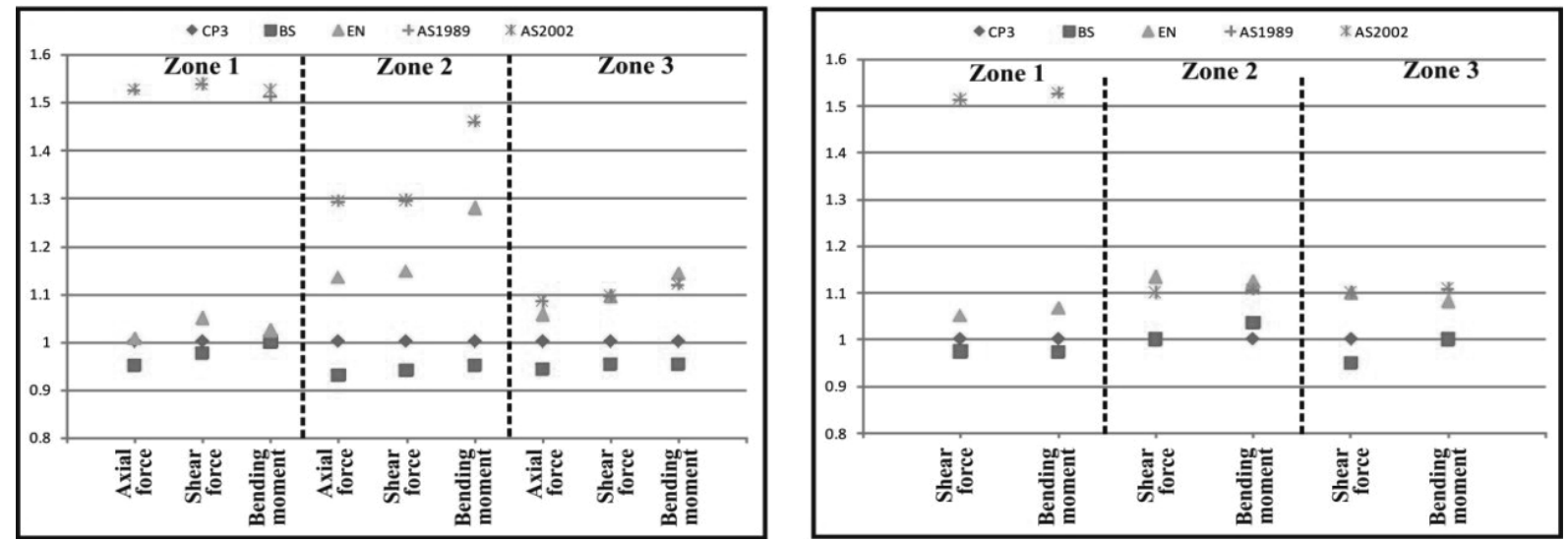

Figure 7- (a) Column loads (b) Beam loads for load combination 1.0G+1.4W (wind flow perpendicular to $30 \mathrm{~m}$ side)

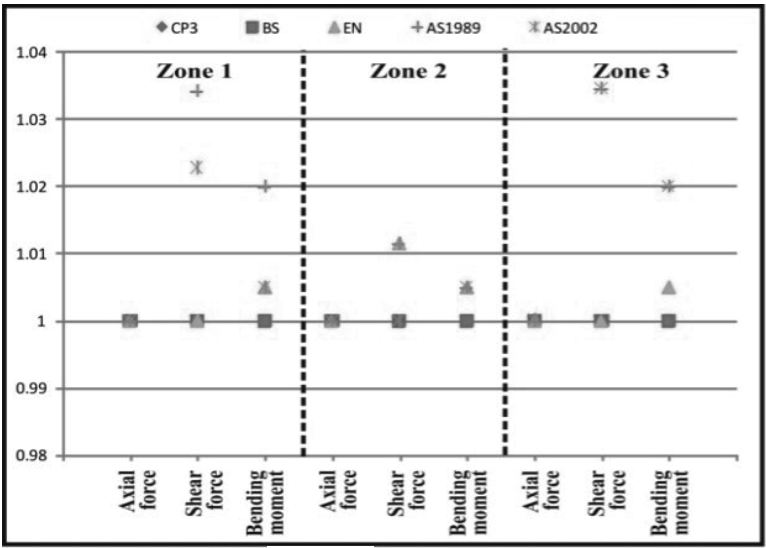

(a)

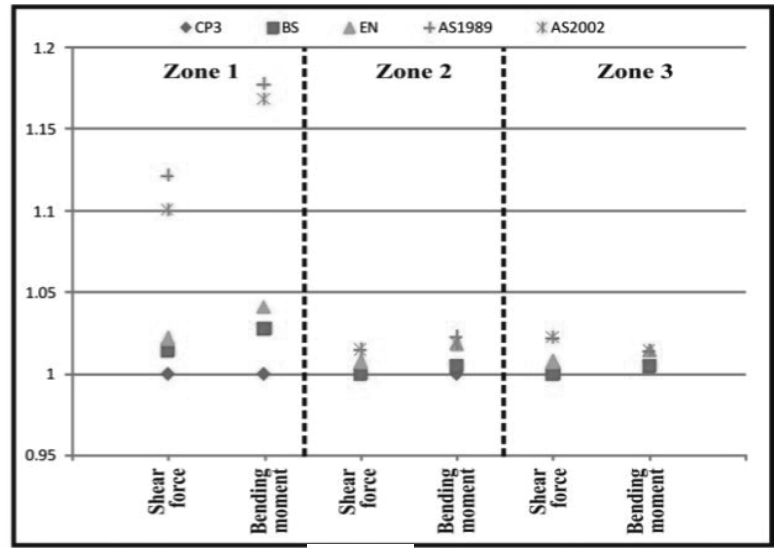

(b)

Figure 8- (a) Column loads (b) Beam loads for load combination 1.4G+1.4W (wind flow perpendicular to $30 \mathrm{~m}$ side)

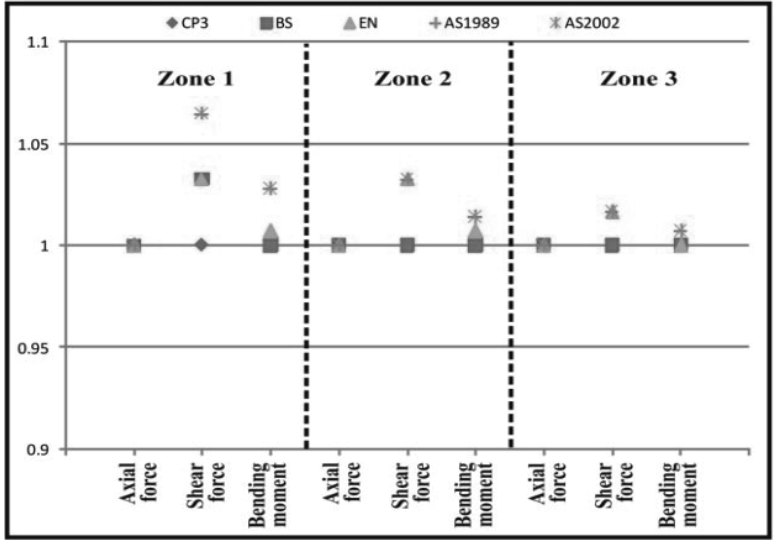

(a)

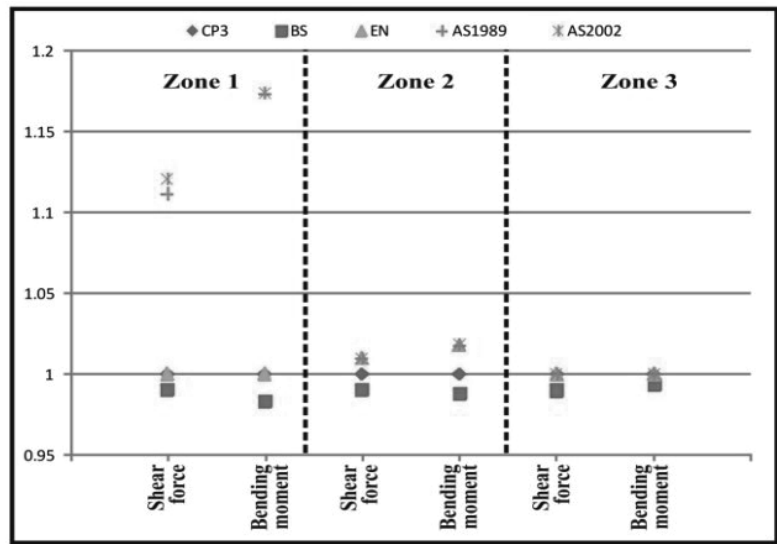

(b)

Figure 9-(a) Column loads (b) beam loads for wind loads only (wind flow perpendicular to 30m side)

According to the FEM analysis, the governing load case for designing structrural members is load combination $1.2 \mathrm{G}+1.2 \mathrm{Q}+1.2 \mathrm{~W}$, which gives the maximum structural load. Except results obtained for both Australian standards in zone 01, other standards generate approximately equal member forces. The maximum difference in column shear force and bending moment is about $10 \%$ in zone 01 when wind flows perpendicular to $60 \mathrm{~m}$ long wall for both Australian standards. That differnce is about $6-7 \%$ when wind flows perpendicular to $30 \mathrm{~m}$ wall. According to Figure 2(b) and 6(b) difference of forces in beams for Australian 
standards can be high as $15-18 \%$ and $5-6 \%$ in zone 01 when wind flows perpendicular to 60 $\mathrm{m}$ side and $30 \mathrm{~m}$ side respectively. This might be due to use of higher terrain-height multiplier in zone 1 to accountit as a cyclone prone area, which is subsequently resulteded higher wind loads. However, the difference of calculated wind loads from different standards is clearly visible from results of load combination $1.0 \mathrm{G}+1.4 \mathrm{~W}$ as the effect of dead load is minimal. The use of higher terrain-height multiplier cause to have $50 \%$ higher shear force and 30\% higher bending moment in columns in zone 1 when wind flow perpendicular to the $60 \mathrm{~m}$ side. For rest of cases, both Australians standards lead to have slightly higher member forces compared to other wind loading standards. This means that use of higher terrain-height multiplier is not indeed necessary unless a designer willing to design highly cyclone resilient building such as cyclone shelters. However when the contribution of dead load has maximum such as in load combination $1.4 \mathrm{G}+1.4 \mathrm{~W}$ column loads are reduced but beams loads are increasing with respective to the previous load combination $1.0 \mathrm{G}+1.4 \mathrm{~W}$. According to the Figure 9, in most of cases resulted column loads are equals for CP 3 Chapter V - Part 2:1972[1] and BS 6399.2:1997[3] standards. However resulted beam loads are slightly lower for BS 6399.2:1997[3] compared to the previous British code of practice. Compare to two British standards, CP 3 Chapter V - Part 2:19721[] and BS 6399.2:1997[3] other three wind loading standards resulted slightly larger member forces for each load combination. This means that calculated wind loads by using Australian and Euro code are higher than the wind load calculated by using British standards.

\subsection{Base reactions}

The summation of wind loads calculated from different wind loads and their overall effect reflect from base reaction as summarized in Table 2.The base shear and base moments valuesvary according to the derived pressure values and their vertical distribution along the height of the building.Therefore, in zone 1, maximum base moment and base shear can be observed for Australian standards, because of their higher wind speeds resulting from higher terrain-height multiplier used in zone1 reulted larger wind loads. These values are almost twice as the values derived from CP 3 Chapter V- Part2:1972 (Figure 10(a)). In zone 2 and zone 3, Euro codes yielded higher base moment as well as base shears values compared to $\mathrm{CP} 3$
Chapter V- Part2:1972 (Table 2). The maximum normalized base shear value is 1.68 observed in zone 2 for Euro code when wind flow perpendicular to $30 \mathrm{~m}$ side. BS 6399.2:1997 resulted base moment approximately equals to CP 3 Chapter V- Part2:1972 in all three zones when wind flow perpendicular to $60 \mathrm{~m}$ long side. However, base shear values are quite different for these two standards. The possible reason might be the vertical distribution of wind loads is different in BS 6399.2:1997 with respect to CP 3 Chapter V- Part2:1972. This argument is verify by the significant differences in base shear and base moment for BS 6399.2:1997 and CP 3 Chapter V- Part2:1972. in all three zones for wind flow perpendicular to 30 m side. BS 6399.2:1997uses Division-by-parts method to distribute wind loadsalong the building height rather than having linear variation with heights. The size of eachdivision depends on the along wind depth of the building.Thus it is varying with the wind direction.According to the Figure 10 (a) and (b) Euro standard yields higher base moment and base shear values in all zones compared to CP 3 Chapter V- Part2:1972. According to the values shown in Table 2, it can be concluded that this might be resulted from combine effect of higher calculated wind loads and the use of divisionby-parts method for pressure distribution in EN 1991-1-4:2005.

\subsection{Maximum shell stress in shear walls}

Similar to member forces, maximum compressive stress in shear walls is observed for both Australian standards in zone 1. From Figures 11(a) and (b), the maximum normalized compressive stress can be as high as 2.1 and 2 for wind flow normal to $60 \mathrm{~m}$ side and $30 \mathrm{~m}$ side respectively. Another striking feature of Figures 11(a) and (b) is all standards contribute larger compressive stress in shear walls compared to CP 3 Chapter V- Part2:1972. That difference is more prominent when wind flow normal to $30 \mathrm{~m}$ side than wind flow perpendicular to $60 \mathrm{~m}$ side. 
Table 2- Base moment and base shear of $48 \mathrm{~m}$ building for two orthogonal directions

\begin{tabular}{|c|c|c|c|c|c|c|}
\hline \multirow[t]{3}{*}{ Wind loading standard } & \multicolumn{6}{|c|}{ Wind flow perpendicular to $60 \mathrm{~m}$ side } \\
\hline & \multicolumn{3}{|c|}{ Base moment $\left(x 10^{6} \mathrm{Nm}\right)$} & \multicolumn{3}{|c|}{ Base shear $\left(x 10^{3} \mathrm{~N}\right)$} \\
\hline & Zone 1 & Zone 2 & Zone 3 & Zone 1 & Zone 2 & Zone 3 \\
\hline CP 3 Chapter V - Part 2:1972 & 121.4 & 91.9 & 60.1 & 4080.8 & 3091.2 & 2020.8 \\
\hline BS 6399.2:1997 & 121.9 & 97.2 & 62.2 & 4687.6 & 3737.9 & 2390.8 \\
\hline AS 1170.2:1989 & 244.6 & 133.2 & 87.1 & 8525.1 & 4752.9 & 3107.3 \\
\hline AS/NZS 1170.2:2002 & 244.4 & 133.2 & 87.0 & 8512.1 & 4812.8 & 3145.5 \\
\hline \multirow[t]{2}{*}{ BS EN 1991-1-4:2005 } & 154.4 & 118.8 & 76.6 & 5937.1 & 4568.8 & 2947.7 \\
\hline & \multicolumn{6}{|c|}{ Wind flow perpendicular to $30 \mathrm{~m}$ side } \\
\hline CP 3 Chapter V - Part 2:1972 & 49.6 & 37.6 & 24.6 & 1669.8 & 1264.6 & 826.8 \\
\hline BS 6399.2:1997 & 63.2 & 49.5 & 31.7 & 2354.2 & 1851.1 & 1186.6 \\
\hline AS 1170.2:1989 & 100.5 & 55.3 & 36.3 & 3428.2 & 1944.2 & 1274.0 \\
\hline AS/NZS 1170.2:2002 & 100.4 & 55.4 & 36.2 & 3421.3 & 1977.2 & 1292.4 \\
\hline BS EN 1991-1-4:2005 & 67.6 & 56.3 & 35.6 & 2557.3 & 2131.0 & 1344.7 \\
\hline
\end{tabular}

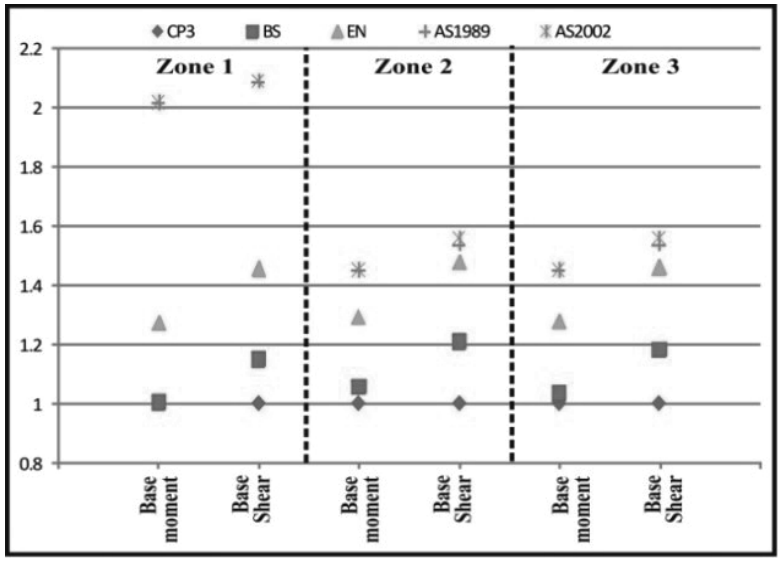

(a)

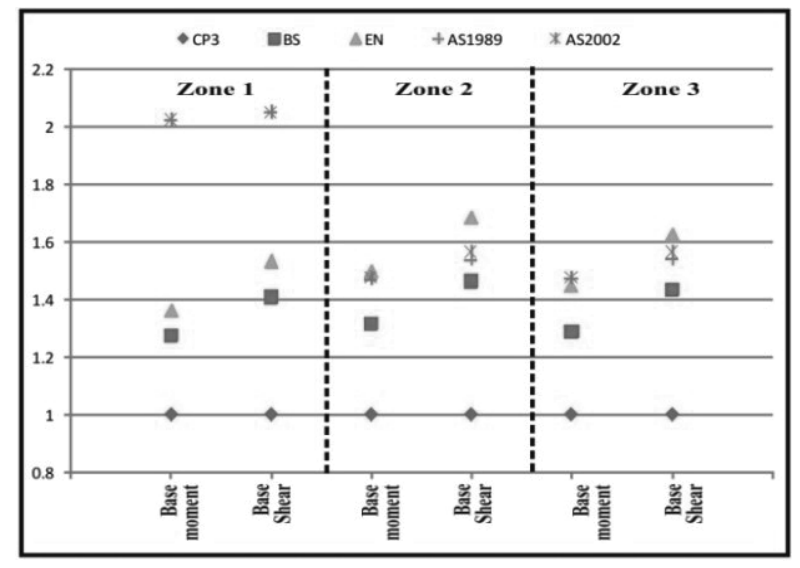

(b)

Figure 10- Base moment and base shear of the $48 \mathrm{~m}$ building (a) Wind flow perpendicular to $60 \mathrm{~m}$ wall (b) Wind flow perpendicular to $30 \mathrm{~m}$ wall

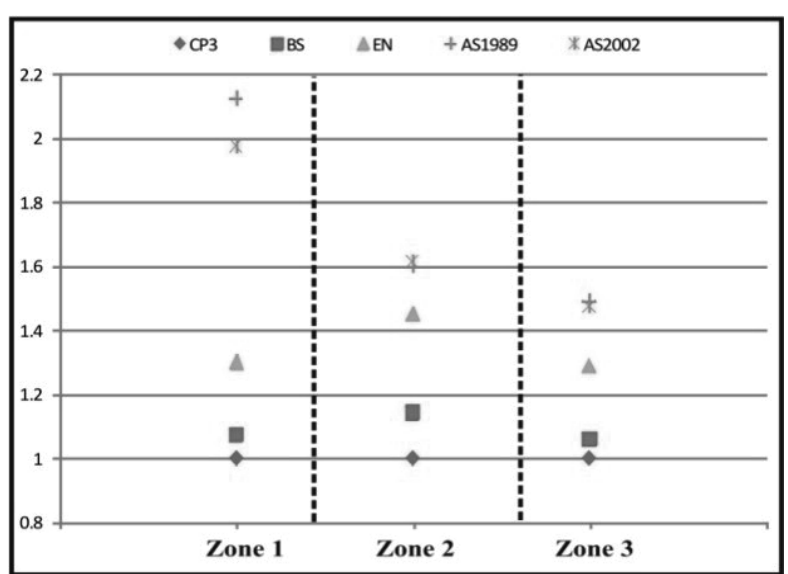

(a)

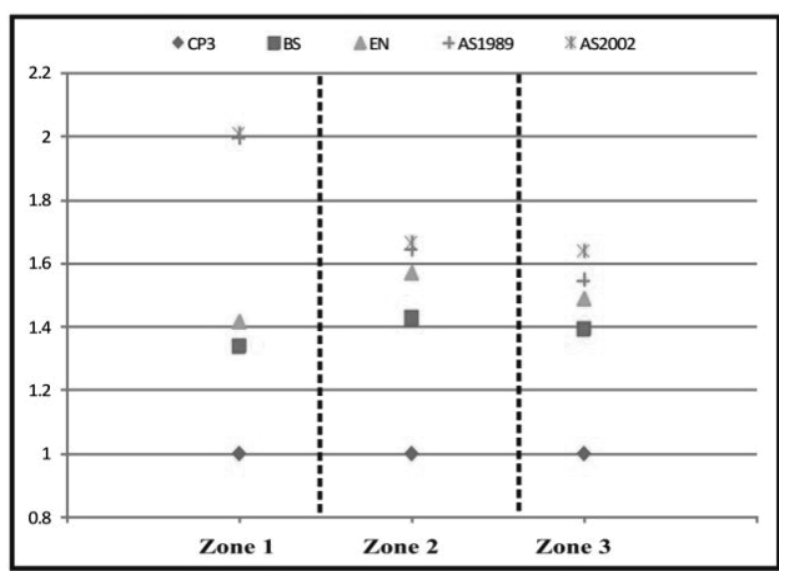

(b)

Figure 11- Maximum shell stress in shear walls of the $48 \mathrm{~m}$ building (a) Wind flow perpendicular to $60 \mathrm{~m}$ side (b) Wind flow perpendicular to $30 \mathrm{~m}$ side 


\subsection{Drift index}

The drift index is calculated for $48 \mathrm{~m}$ height building in order to determine the degree of wind sensitivity of the building. The maximum deflection in serviceability limit condition is obtained by using3-D finite element model with wind loads calculated by using different standards. According to the BS 8110-Part 2: 1985[19] the maximum allowable deflection is calculated as hs/500, where hs is the storey height of a single story building. Therefore, in zone 1. However, these differences were reduced in zone 2 and 3 . In these zones 2 and 3, Euro codes yielded higher stresses due to higher wind loads derived from the code.

4. Base shear and base moments are two major measurements on determining the effects of wind loads, which are directly combine with the wind load values and their distribution along the height of the building. Higher base

Table 3 - Drift index for 48m height building in zone 1, 2 and 3

\begin{tabular}{|l|c|c|c|}
\hline \multicolumn{1}{|c|}{ Wind loading standard } & \multicolumn{3}{|c|}{ Drift index } \\
\cline { 2 - 4 } & Zone 1 & Zone 2 & Zone 3 \\
\hline CP 3 Chapter V - Part 2:1972 & $1 / 2597$ & $1 / 3525$ & $1 / 5208$ \\
\hline BS 6399.2:1997 & $1 / 2531$ & $1 / 3311$ & $1 / 5155$ \\
\hline AS 1170.2:1989 & $1 / 1290$ & $1 / 2387$ & $1 / 3636$ \\
\hline AS/NZS 1170.2:2002 & $1 / 1290$ & $1 / 2387$ & $1 / 3636$ \\
\hline BS EN 1991-1-4:2005 & $1 / 2087$ & $1 / 2710$ & $1 / 4202$ \\
\hline
\end{tabular}

maximum allowable deflection values are $96 \mathrm{~mm}$ at top of $48 \mathrm{~m}$ height building. However, observed top deflection for each test cases was significatly less than $96 \mathrm{~mm}$, which ensure that there is no excessive deflection of the building. The average drift index is defined as a ratio betweenmaximum deflections to total height of the building. The drift index values are shown in Table 2.The generally accepted average drift index limit for the high rise building is $1 / 500$ [3]. By reference to Table 2, it can be clear seen drift index is not exceeding the limit for $48 \mathrm{~m}$ tall building.

\section{Conclusion}

Major findings of this study can be presented as followings;

1. Structural loads are varying according to the wind loads derived from the standards.

2. Both Australian standards give higher forces in zone 1 due to use of higher terrain multiplier for cyclonic areas. Unless designing an important post disaster structure, this factor can be omitted to have a more economical design.

3. Same trend can be seen in maximum stresses in concrete shell of shear wall in both models. Both Australian standards gave higher stresses because of their higher wind pressure values moment and base shear obtained from British and Euro codes because of they use division by parts rule for distributes wind loads along the height of the building.

5. Division - by - parts rule trends alter the vertical variation of wind loads significantly.Therefore, necessary to balance the derived wind loads and its linrear vertical variation carefully.

6. For the medium -rise builing used in this study does not exceed the drift limit irespective to building location in any wind zone.

\section{Acknowledgement}

Authors of this paper like to express their gratitude towards National Disaster Management Center (NDMC), who provided financial support throughout this study. They also wish to thank the Department of Civil Engineering, University of Moratuwa to provide necessary resources to conduct this research successfully. 


\section{Refferences}

1. CP 3 Chapter V: 1972 , Code of basic data for the design of buildings chapter V. Loading, Part 2 Wind Loads, British Standard Institution, London.

2. British Standard: Eurocode 1: Actions on Structures - Part1- 4: General actions - wind actions; BS EN 1991-1-4:2005, British Standard Institution, London.

3. British Standard: Loading for Building- Part 2: Code of Practice for Wind Loads; BS 63992:1997, British Standard Institution, London.

4. Clarke, A. G., Swane, R.A., Schneider, L. M, Shaw, P. J. R., Report of Technical Assistance to Sri Lanka on Cyclone Resistant Construction, Vol 1, Part 1 -4, 1979.

5. Design of Buildings for High Winds, Sri Lanka, Sri Lankan Ministry of Local Government, Housing and Construction, 1980.

6. Wijeratne, M. D., Jayasinghe, M. T. R., "Wind Loads for High-Rise Buildings Constructed in Sri Lanka", Transactions Part 2- Institution of Engineers, Sri Lanka, 1998, pp 58-69.

7. Premachandra, W. R. N. R., "Study of New Wind Loading Code to be Adopting on Sri Lanka", M.Sc Thesis, Graduate school, Kasetsart University, 2008.

8. Cyclone Events 1900 - 2000, Available Source, www.meteo.gov.lk, last acces on 03/09/2010

9. Mendis, P., Ngo, T., Hariots, N., Hira, A., Samali, B., Cheung, J., Wind Loading on Tall Buildings, Electronic Journal of Structural Engineering special issue; Loading on structures, 2007. pp 41-54.

10. Tamura, Y., Holmes, J. D., Krishna, P., Guo, Lu., Katsumura, A., Comparison of Wind Loads on Medium Rise Building According to the AsiaPacific codes/.standards, The seventh AsiaPacific Conference on Wind Engineering(APCWE-VII), Taipe, Taiwan, November 08-12, 2008.

11. Holmes, J. D., Tamura, Y., Krishna, P., Wind Loads on Low, Medium and High-Rise Buildings by Asia - Pacific codes, The Fourth International Conference on advances in wind and structures (AWAS'08), Jeju, Korea, May 2931-, 2008.

12. Holmes, J. D., Tamura, Y., Krishna, P., Comparison of Wind Loads Calculated by Fifteen Different Codes and Standards, for Low, Medium and High-Rise Buildings, 11th American conference on wind engineering, San Juan, Puerto Rico, June 22-26, 2009.

13. Kola, S., Comparison of Wind Load Standards, M.Sc. Thesis, Texas Tech University, United States, 1995.
14. Australian standard for wind loads ; AS 1170.2:1989, Standards Australia, New South Wales.

15. Australian and New Zealand Standard: Structural design actions Part 2: Wind actions; AS/NZS 1170.2:2002, Standards Australia, New South Wales.

16. CSI Analysis Reference Manual, Computers and Structures Inc., Berkeley, California, USA, 2013.

17. Cook, N. J., Wind loading, A Practical Guide to BS 6399-2 Wind loads for buildings, Thomas Telford, 1999.

18. Narayan R. S., Cook, N. J., Smith B. W., Rees, E. J., Blackmore, P., Report on the Calibration of Euro code for wind loading (BS EN 1991 - 4) and its UK National Annex against the current UK wind code (BS 6399: Part 2:1997), Report submitted to Department for Communities and Local Government (DCLG), UK, 2007.

19. British Standard: Structural use of concrete- Part 2: Code of practice for special circumstances; BS 8110- 2:1985, British Standard Institution, London. 
